\title{
A escrita do gênero textual poema no ensino fundamental I
}

\author{
The writing of the poem textual gender in elementary school I \\ La escritura del género textual poema en la educación primaria
}

\author{
Flávio Renato Santos \\ Andréia Osti** \\ Neide de Brito Cunha*
}

\section{Resumo}

Este artigo, de natureza qualitativa, discute a escrita do gênero textual poema no Ensino Fundamental, buscando avaliar seus componentes internos (conteúdo temático, estilo de linguagem e estrutura composicional), relacionando-os à sequência didática elaborada e executada por uma docente. O estudo inicia-se com um breve resgate da história do ensino da escrita, do início das práticas de letramento e do ensino dos gêneros textuais nas escolas brasileiras. Além disso, recuperam-se trabalhos sobre a importância das sequências didáticas para o ensino dos gêneros. Por fim, observa-se a atividade de escrita do gênero textual poema por alunos de um quinto ano de escola pública, cujos textos são descritos e analisados. Os resultados obtidos apontam, positivamente, para a adequação ao tema e à estrutura composicional requeridos, porém, indicam fragilidades, sobretudo, no estilo de linguagem adotado. A análise dos resultados sugere relação direta entre as atividades da Sequência Didática e os componentes desenvolvidos nos poemas.

Palavras-chave: Gênero Textual. Poema. Produção de texto. Ensino Fundamental. Sequência Didática.

Recebido em 26/07/2019 - Aprovado em 28/02/2020

http://dx.doi.org/10.5335/rep.v27i2.11442

Mestre em Educação pela Universidade Estadual Paulista Júlio de Mesquita Filho (Unesp). Professor de Língua Portuguesa no colégio Claretiano, Rio Claro-SP e na rede estadual de Educação do estado de São Paulo, Brasil. Orcid: https://orcid.org/0000-0001-7957-3757. E-mail: flavioguap@hotmail.com.

** Doutora em Educação pela Faculdade de Educação da Universidade Estadual de Campinas (UNICAMP). Pós-doutoramento em Psicologia na Universidade São Francisco, USF. Professora do Departamento de Educação da Universidade Estadual Paulista (Unesp) e no PPGEdu UNESP, Rio Claro, Brasil. Orcid: https://orcid.org/0000-0002-7605-2347. E-mail: andreia.osti@unesp.br

*** Doutora em Psicologia. Pós-doutorado em Educação pela UNICAMP e em Avaliação Psicológica Educacional pela USF. Coordenadora adjunta do Mestrado em Educação da Universidade do Vale do Sapucaí e docente no Mestrado Profissional do Centro Paula Souza e da Fatec de Bragança Paulista, Brasil. Orcid: https://orcid.org/0000-0003-49454495. E-mail: neidedebritocunha@gmail.com 


\section{Abstract}

This article, of qualitative nature, discusses the writing of the textual gender poem in Elementary School, trying to evaluate its internal components (thematic content, language style and compositional structure), relating them to the Didactic Sequence elaborated and executed by the teacher. The study begins with a brief rescue of the writing teaching history, the beginning of literacy practices and the teaching of textual genders in Brazilian schools. In addition, recovered work about the importance of the Didactic Sequences for the teaching of genders. Finally, we observe the writing activity of the textual gender poem by fifth grade students in Elementary school, whose texts are described and analyzed. The obtained results point, positively, to suit the theme and the required compositional structure, but indicate weaknesses in the language style. The analysis of the results suggests a direct relationship between the activities of the Didactic Sequence and the developed components in the poems.

Keywords: Textual Gender. Poem. Production of Text. Elementary School. Didactic Sequence.

\section{Resumen}

Este artículo cualitativo discute la redacción del género textual poema en la escuela primaria, buscando evaluar sus componentes internos (contenido temático, estilo de lenguaje y estructura compositiva), relacionándolos con la secuencia didáctica elaborada y realizada por un maestro. El estudio comienza con una breve revisión de la historia de la enseñanza de la escritura, el comienzo de las prácticas de alfabetización y la enseñanza de géneros textuales en las escuelas brasileñas. Además, se está recuperando el trabajo sobre la importancia de las secuencias didácticas para la enseñanza de géneros. Finalmente, se observa la actividad de escritura del género poema por parte de estudiantes de quinto año de escuela pública, cuyos textos se describen y analizan. Los resultados apuntan positivamente a la adecuación al tema requerido y la estructura compositiva, sin embargo, indican debilidades, sobre todo, en el estilo de lenguaje adoptado. El análisis de los resultados sugiere una relación directa entre las actividades promovidas en la secuencia didáctica y los componentes bien desarrollados en los poemas.

Palabras clave: Género textual. Poema. Producción de texto. Educación primaria. Secuencia Didáctica.

\section{A escrita de gêneros textuais nas escolas}

Sabe-se que a preocupação com o ensino da escrita de textos funcionais nas escolas é muito recente. Os estudos de Mortatti (2006) revelaram que a escola brasileira, desde o século XIX, período em que as aulas régias foram substituídas pela escola obrigatória, leiga e gratuita, até o início da década de 1980, praticamente não ensinava a escrever textos com os quais crianças e adolescentes interagiam em sua vida cotidiana. A autora revela que, durante quase dois séculos, privilegiou-se o ensino da leitura, considerando-se o ato de escrever como espontâneo e natural, ocorrendo em função apenas do aprendizado da leitura. Assim, as práticas de escrita, exercidas pela escola, restringiram-se, por séculos, aos treinos de caligrafia, às cópias, aos ditados, às redações/composições escolares etc., cujo propósito não era ensinar os gêneros textuais que circulavam na sociedade, e, sim, promover o mero aprimoramento linguístico. 
Tal realidade, segundo Soares (2006), começou a mudar com as discussões sobre letramento que chegaram ao Brasil na década de 1980. Segundo a autora, a sociedade da época percebeu que apenas a alfabetização (ensino da codificação e da decodificação das letras do alfabeto) não era suficiente para que as pessoas utilizassem a escrita com sucesso em práticas sociais. Muitas pessoas, então, saiam da escola, naquele período, sabendo as letras do alfabeto, mas incapazes de ler e de escrever textos necessários às suas ações cotidianas. Assim sendo, percebeu-se a necessidade de letrar, de ensinar a leitura e a escrita de modo funcional, formando sujeitos capazes de participar dos mais diversos eventos sociais de uso da linguagem escrita. Dessa forma, o processo de letramento, juntamente com a alfabetização, passou a fazer parte do processo de ensino da escrita, seguindo o entendimento dos Parâmetros Curriculares Nacionais (PCN) (BRASIL, 1997) de que:

[...] ensinar a ler e a escrever somente pelo estudo isolado de letras, palavras ou frases representaria a descontextualização do processo de ensino-aprendizagem, já que se retira o objeto de estudo (a linguagem escrita) do seu ambiente natural (o texto). O que se propõe também não é a exclusão do estudo segmentado das letras, das palavras ou das frases e sim que ele seja contextualizado, que o aprendiz compreenda que essas partes integram o todo que, no caso, sempre será um texto, seja ele complexo, como um romance, ou mais simples, como um bilhete (p. 29).

Nesse sentido, a alfabetização e o letramento passaram a ser entendidos como processos simultâneos e complementares para a formação do proficiente usuário da escrita. Tfouni (2005, p. 9, grifo do autor) sintetiza a relação entre alfabetização, letramento e escrita da seguinte forma: "a relação entre eles é aquela do produto e do processo: enquanto os sistemas de escrita são um produto cultural, a alfabetização e o letramento são processos de aquisição de um sistema escrito". Essa mesma concepção de alfabetização e de letramento é também compartilhada pelo Ministério da Educação (MEC), já que esse entende que a alfabetização envolve a apropriação do sistema de escrita (princípios alfabéticos e ortográficos) e que o letramento deve ser compreendido:

[...] como o processo de inserção e participação na cultura escrita. Trata-se de um processo que tem início quando a criança começa a conviver com as diferentes manifestações da escrita na sociedade (placas, rótulos, embalagens comerciais, revistas, etc.) e se prolonga por toda a vida, com a crescente possibilidade de participação nas práticas sociais que envolvem a língua escrita (leitura e redação de contratos, de livros científicos, de obras literárias, por exemplo) (BRASIL, 2012, p. 12-13).

Constatou-se, então, que o ensino da escrita de textos voltado meramente para o aperfeiçoamento linguístico pouco contribuía com a formação plena do escritor. 
Ou seja, percebeu-se que a escola "produzia" muitos analfabetos funcionais, indivíduos que dominavam as técnicas do ler e do escrever, todavia, eram incapazes de usá-las em boa parte das atividades sociais que as envolviam. Assim sendo, com tais mudanças de concepção de ensino e de adoção do letramento como prática necessária para a inserção dos sujeitos na cultura escrita, reconheceu-se também a urgência do ensino dos gêneros textuais, já que esses são entendidos como materialização dos textos que ocorrem no cotidiano, ou seja, os gêneros textuais apresentam-se como formas que concretizam toda e qualquer comunicação verbal, a qual não ocorre senão por meio deles, o que torna obrigatório seu ensino.

Neste sentido, Bakhtin (2003) explica que os gêneros textuais são construções que, para atender determinadas especificidades de um campo discursivo, assumem conteúdo temático, estrutura de linguagem e construção composicional relativamente estáveis. Ou seja, as diferentes atividades humanas, mediadas pelo uso das diferentes linguagens, necessitam, muitas vezes, dos gêneros textuais (escritos ou orais) para que ocorram, os quais apenas ocorrerão com êxito se respeitarem as características próprias do campo discursivo no qual é utilizado.

Os estudos de Marcuschi (2002) e Schneuwly e Dolz (2004) seguem nessa mesma direção. Marcuschi (2002) considera que toda comunicação verbal depende da ocorrência de gêneros textuais; para o autor, é por meio deles que as ações sociodiscursivas "dizem" e "agem" sobre o mundo. Tais ações se dão de modo "relativamente estáveis realizadas em textos situados em comunidades de práticas sociais e em domínios discursivos específicos" (MARCUSCHI, 2002, p. 24). Isso significa que, para funcionar em determinados espaços sociais, é preciso que haja certa; padronização, isto se dá, como supracitado, em relação aos conteúdos e conhecimentos dizíveis, à estrutura comunicativa (o "esqueleto" composicional) e ao estilo de linguagem empregados no texto, que, com tais características, se concretizam em um gênero textual (SCHNEUWLY; DOLZ, 2004).

Conclui-se, então, que todas as variantes envolvendo a escrita dos gêneros textuais devem ser ensinadas nas escolas. Para Marcuschi (2002, p. 32-33), "todos os textos se manifestam sempre num ou noutro gênero textual", assim, "um maior conhecimento do funcionamento dos gêneros textuais é importante tanto para a produção como para a compreensão". Analogamente, Val (2007), reconhecendo que toda comunicação verbal se dá por meio dos gêneros textuais, ressalta a necessidade do ensino dos gêneros textuais nas escolas, uma vez que, segundo a autora, muitos estudantes chegam à escola com pleno domínio de gêneros menos elaborados, principalmente os orais, contudo, é, por meio da escola, que aprendem 
gêneros novos ou mais elaborados, os quais não seriam aprendidos fora dela, seja pela complexidade, seja pelo desconhecimento de sua existência.

Assim sendo, acredita-se que o ensino dos gêneros textuais significa sobretudo possibilitar que os sujeitos participem dos mais diversos campos de atividades humanas que usam a escrita, inclusive daqueles de maior prestígio social. Portanto, aprender a ler e a escrever o maior número de gêneros textuais possíveis torna-se condição importante para alcançar mudanças e melhorias nas condições sociais dos homens. Evidencia-se, então, o importante papel da escola de promover a continuidade do processo de letramento por meio do ensino sistemático dos gêneros para que crianças e adolescentes possam cada vez mais participar dos eventos sociais mediados pela escrita.

Contudo, é preciso ressalvar que não é suficiente que a escola substitua as frases soltas pelo simples ensino dos conteúdos, linguagem e estrutura necessária em cada gênero textual para que o problema do ensino da linguagem escrita esteja resolvido. Segundo Santos, Mendonça e Cavalcante (2007), é necessário que se aborde, nas escolas, tanto os componentes internos dos gêneros textuais quanto seus componentes externos para que a escrita seja, efetivamente, aprendida. Isso significa que o ensino do conteúdo temático, da linguagem e da estrutura composicional de um gênero deve ocorrer em consonância com o estudo das motivações externas que geram tais características. Para tanto, deve-se conduzir o aluno a compreender quem são o campo discurso, os usuários envolvidos, o contexto social, a cultural, o aspecto geográfico etc. que determinam a escolha de um determinado gênero textual, de seu conteúdo, de suas estrutura e linguagem.

Portanto, não é possível, por exemplo, ensinar, nas escolas, a linguagem utilizada em um gênero textual sem abordar as motivações externas para a adoção desta linguagem. Nesse sentido, surgem, para atender a essa exigência, as Sequências Didáticas (SD), discutidas, sobretudo, por Schneuwly e Dolz (2004), as quais revelam-se fundamentais para o ensino dos gêneros textuais, já que, se bem elaboradas e aplicadas, contemplam o ensino de todos os seus componentes (externos e internos).

\section{0 uso das sequências didáticas para 0 ensino dos gêneros textuais}

Diante da necessidade do ensino dos aspectos internos (conteúdo temático, estilo de linguagem, estrutura etc.) e externos (finalidade do texto, usuários, contexto social, cultural, regional etc.) dos gêneros textuais nas escolas, o uso das Sequências Didáticas (SD) mostra-se necessário a tal propósito, já que, segundo 
Schneuwly e Dolz (2004), essa ferramenta dispõe de um conjunto de atividades escolares programadas sistematicamente para que o aluno aprenda um determinado gênero. As SD têm a finalidade de auxiliar o trabalho do professor, levando o aluno à apropriação e à consequente utilização dos gêneros nos mais diferentes espaços sociais, nesse sentido, as SD devem possibilitar, ao aluno, o aprendizado tanto dos gêneros desconhecidos quanto daqueles conhecidos, porém, difíceis de serem utilizados (orais ou escritos).

O reconhecimento das SD como ideais ao ensino dos gêneros se dá pela plasticidade dos procedimentos nelas adotados para o ensino: toda a SD se constrói em função do gênero a ser ensinado e do grupo para qual será utilizada. Assim sendo, cada SD terá características peculiares que devem, de acordo com Schneuwly e Dolz (2004), atender a alguns pressupostos: 1. A adaptação da escolha do gênero e das situações de comunicação às capacidades dos alunos; 2. Antecipação das transformações possíveis e de etapas que possam ser transpostas; 3. Simplificação de tarefas para que não excedam as capacidades iniciais das crianças; 4 . Esclarecimento dos objetivos da escrita e do caminho a ser percorrido; 5 . Tempo suficiente para que ocorra a aprendizagem; 6 . Organização das intervenções para que ocorram transformações/avanços na escrita dos textos; 7. Organização de momentos de colaboração entre os alunos para que contribuam entre si com as transformações; 8. Avaliação das transformações ocorridas.

Em síntese, a utilização das SD passa por quatro etapas que devem ser contempladas em sua elaboração: 1. Apresentação inicial (conhecimento do projeto de escrita a ser executado: apreciar o gênero - o que envolve sua leitura e estudo, a quem se dirige, a forma que ele assume, quais sujeitos o utilizam etc.); 2. Primeira produção escrita (responsável pela manifestação das primeiras representações que o aluno-escritor tem do gênero, funcionando como "termômetro" para que o professor identifique quais capacidades de escrita ainda precisam ser desenvolvidas; 3. Módulos de intervenção (atividades que buscam solucionar os problemas encontrados); 4. Produção final (acompanhamento dos avanços obtidos).

As vantagens da utilização das SD como estratégias de ensino foram observadas em algumas pesquisas. O estudo qualitativo desenvolvido pela pesquisa-ação de Galvão (2015) revelou avanços significativos no aprendizado dos gêneros por alunos do $5^{\mathrm{o}}$ ano do Ensino Fundamental, explicitando sobretudo avanços das primeiras versões dos textos escritos em relação à versão definitiva. A pesquisa, realizada com 66 alunos de uma escola pública, valeu-se de diferentes instrumentos, tais como questionários, observações, leituras e escritas de textos, para observar o 
desenvolvimento da escrita em diferentes gêneros textuais: carta, bilhete, música, poesia, fábula e conto. A análise dos 90 textos escritos e dos 58 questionários respondidos revelou que houve avanço significativo na leitura e na escrita dos gêneros no que se refere à construção de informações explícitas e implícitas no texto, à inferência de sentido de palavras e expressões, à relação de lógica entre partes de textos de diferentes gêneros e temáticas, além da relação entre textos verbais e não verbais (GALVÃO, 2015). Avaliou-se que as SD contribuíram com:

[...] O planejamento dos textos considerando o contexto de produção; a organização do texto dividindo-o em tópicos, parágrafos ou estrofes; a produção de diferentes gêneros com autonomia, atendendo a distintas finalidades; além da pontuação, estruturação dos períodos e utilização de recursos coesivos para organização das ideias e fatos (GALVÃO, 2015, p. 333).

A pesquisa ainda constatou que as SD foram capazes de motivar a produção escrita em sala de aula, uma vez que se observou o maior envolvimento dos discentes nas atividades de escrita. Diante de todos os resultados, concluiu-se que o aprendizado e o aperfeiçoamento da escrita por meio das SD são possíveis com quaisquer gêneros textuais, já que o estudo fez uso de um número diversificado de gêneros e observou avanço em todos (GALVÃO, 2015).

Analogamente, o estudo desenvolvido por Souza (2015) constatou resultados muito positivos nas escritas de trinta alunos do Ensino Fundamental de uma escola pública quando utilizada a SD para o ensino dos gêneros textuais Carta Pessoal e Carta do Leitor. A aplicação da SD (apresentação e estudo dos gêneros, a produção inicial - diagnóstica-, os módulos de intervenção e a reescrita da versão definitiva dos gêneros), de acordo com a pesquisa, provocou maior interesse dos alunos pela escrita: constatou-se melhoria da atenção dos alunos no processo de leitura, maior participação nas discussões, no processo de escrita do texto, na análise linguística, na autocorreção e na reescrita do texto, corroborando a formação escritora daqueles sujeitos. $\mathrm{O}$ estudo também observou melhorias na construção dos gêneros textuais escritos: as comparações entre a primeira e a última versão, realizadas como parte do percurso metodológico adotado pela pesquisadora, revelaram progressos significativos nos dois gêneros escritos. As versões finais das cartas pessoais mostraram avanços, sobretudo, no que se refere às soluções gramaticais encontradas pelos alunos, uma vez que essa era a maior dificuldade no gênero. Além disso, houve melhoria na organização estrutural do gênero: saudação, desenvolvimento do conteúdo temático, despedida etc. Na escrita da carta do leitor, as mudanças mais significativas ligavam-se à utilização da linguagem (SOUZA, 2015). 
Diante das constatações supramencionadas em torno da importância das SD para o ensino de gêneros textuais é que esse estudo se interessou por observar como ocorre a escrita de um gênero textual ao final do Ensino Fundamental I, a partir de uma proposta de escrita elaborada e aplicada pelo docente. Assim sendo, considerando o contexto de produção em que aconteceu o ensino do gênero, discute-se aqui o quanto os alunos conseguiram produzi-lo respeitando as características de estilo de linguagem, conteúdo temático e estrutura composicional relativamente estáveis de acordo com o campo discursivo no qual ocorre.

\section{A pesquisa de campo}

A razão deste estudo qualitativo está no objetivo geral desta pesquisa: avaliar os componentes internos (conteúdo temático, estilo de linguagem e estrutura composicional) de um gênero textual escrito por alunos do Ensino Fundamental I em uma escola pública a partir de uma proposta elaborada e aplicada pelo docente titular. Realizou-se, então, a pesquisa de campo para compreender o quanto os gêneros textuais, escritos pelos discentes em situações cotidianas propostas pelo professor, estão adequados no que se refere às suas características formais internas. Assim sendo, espera-se provocar uma reflexão sobre a capacidade escritora de gêneros textuais por alunos nas escolas de Ensino Fundamental I.

Para melhor entender como os alunos estão escrevendo no Ensino Fundamental I, decidiu-se observar o processo de escrita de um gênero textual no $5^{\circ}$ ano, porque é o último ano escolar e entende-se que o trabalho sistemático com ensino da escrita dos gêneros já esteja mais avançado. Tornaram-se, então, participantes dessa pesquisa 21 alunos, que aceitaram participar e tiveram autorização de seus responsáveis, e a docente da turma, que também autorizou o trabalho. $\mathrm{O}$ estudo foi desenvolvido em uma escola municipal do interior do estado de São Paulo. Vale ressaltar que esse estudo apenas teve iniciou após a aprovação do Comitê de Ética em Pesquisa em Seres Humanos (parecer n⿳0 1.185.377), de acordo com a Resolução CNS 466/12.

Os instrumentos de pesquisa foram decididos em função do propósito de avaliar a escrita dos alunos e de observar o desenvolvimento das atividades em sala de aula. Assim sendo, foram utilizados o diário de observação para relatar a atividade de escrita desenvolvida, uma Escala de Observação Sistemática (elaborada pelos pesquisadores) para orientar o olhar da pesquisa e auxiliar na interpretação da SD 
e, por fim, as versões finais das escritas dos discentes (21 textos) para avaliar as características do gênero escrito.

Para descrição e análise dos resultados das escritas dos alunos, dois aspectos foram considerados: o primeiro diz respeito ao contexto de produção (as intenções expressas pela professora na apresentação da proposta de escrita, o espaço social: a cidade e a escola, e o tempo: momento histórico) no qual a escrita aconteceu, ou seja, os fatores que podem ter interferido para que o gênero textual fosse escrito de uma ou de outra forma; e o segundo aspecto considerado para a leitura e a interpretação dos dados foi o ponto de partida e o modo como foi elaborada e aplicada a SD pelo docente, já que isso pode determinar as características do gênero escrito.

\section{A sequência didática para 0 ensino de poemas}

As atividades de escrita do gênero textual ocorreram em três diferentes dias, segundo o planejamento feito pela docente do grupo. A professora decidiu trabalhar com o gênero textual poema para que continuasse o trabalho que, segundo ela, vinha sendo feito e estava gerando bons resultados.

No primeiro dia de observação da atividade, a professora iniciou sua Sequência Didática anunciando, aos alunos, a escrita do gênero poema e do tema "O lugar onde vivo" e revelando o propósito de apresentá-lo no sarau da escola. Lembrou-os também que já haviam estudado poemas em outras situações e que era um gênero próximo à paródia, gênero trabalhado na semana anterior. A docente prosseguiu como uma discussão sobre a relação dos alunos com o gênero: o que já haviam lido, do que tratavam, se gostaram etc. Em seguida, o poema "Prazer de Poeta", de Mardilê Friedrich Fabre, foi lido, discutiu-se o título do poema, o conceito de estrofes, de versos e de rimas e como se organizavam tais componentes no poema (além da discussão, os discentes também responderam a um questionário). Posteriormente, passaram a tratar do vocabulário: buscar os significados de termos desconhecidos, o que subsidiou a discussão sobre a temática do poema lido. Por fim, a professora atribuiu duas lições de casa aos alunos: encontrarem poemas com apenas uma estrofe e pesquisarem sobre o lugar onde vivem: clima, paisagem, pessoas, coisas boas e/ou ruins.

No segundo dia de observação, ocorreu a escrita dos poemas. A professora não conferiu ou retomou a tarefa solicitada anteriormente, mas começou a aula elogiando o envolvimento dos alunos com os poemas, pois estavam escrevendo-os espontaneamente em casa. Prosseguiu, então, com a leitura e a interpretação dos 
poemas "Cidadezinha", de Mário Quintana e "Milagre no Corcovado" (de Ângela Leite de Souza), os quais abordavam o tema "O lugar onde vivo". Em seguida, ocorreu a escrita, que foi orientada, pela docente, a fim de que acontecesse em versos, em estrofes e com rimas. A docente também ressaltou a importância do tema, pediu para que, ao escrever, recuperassem o bairro, a casa ou outros espaços que gostassem. Durante o trabalho dos alunos, houve duas intervenções da professora: primeiro, ela colocou 5 questões na lousa para avaliação do tema, das estrofes, dos versos e das rimas do poema que os alunos estavam escrevendo, depois insistiu para que os alunos não se restringissem a um único espaço da cidade, pedia para alternarem suas escritas sobre diferentes lugares. Por fim, a aula terminou com a leitura e com a discussão do poema "Poesia das capitais", de Luiz de Miranda.

No último dia de observação, houve a reescrita dos poemas. A professora começou a atividade lendo poemas aleatórios e, posteriormente, fez a entrega dos poemas dos alunos por ela corrigidos e solicitou a reescrita. Contudo, a docente havia feito apenas correções ortográficas e gramaticais e não solicitou nenhuma revisão por parte dos alunos. Portanto, os alunos, nessa atividade, apenas "passaram a limpo" seus textos, solucionando os problemas indicados pela docente referentes à ortografia, à acentuação e à pontuação. Em apenas um ou outro texto a docente pediu para reorganizar a estrutura do poema, alterando o texto construído em parágrafos para um texto organizado em versos. Não houve também nenhuma correção, intervenção ou solicitação de revisão do conteúdo temático ou do estilo de linguagem do poema. Em síntese, a atividade do dia restringiu ao exercício de "passar a limpo" os textos, eliminando erros apontados pela professora e, enquanto isso acontecia, ela lia oralmente alguns poemas. Não ocorreu também a avaliação, por parte da docente, da escrita final dos poemas, ou seja, as versões finais dos textos escritos não foram lidas ou discutidas individualmente ou em grupo para avaliar os avanços e apontar possíveis melhorias.

\section{A escrita de poemas no ensino fundamental I}

Sabe-se do caráter normativo que qualquer avaliação possui, elas ocorrem sempre a partir de escolhas que podem se manifestar menos ou mais arbitrárias. Quando se trata da avaliação da escrita de gêneros textuais deve-se, então, dar atenção aos componentes internos ao gênero necessários para que ele se manifeste como tal, ao mesmo tempo que se deve considerar os componentes externos que motivam sua escrita e determinam a construção textual do gênero textual escrito. 
Assim, para avaliar a escrita de um poema, é preciso, primeiramente, considerar a multiplicidade de formas que esse gênero pode assumir: um dos mais antigos gêneros da história da escrita, o poema, ao longo dos séculos, sofreu e sofre transformações em todos seus componentes - assume novas construções composicionais, adota diferentes conteúdos temáticos e estilos de linguagem diversos a depender da história, do espaço sociocultural, das intenções artísticas, estéticas, políticas, econômicas etc. em que ocorre.

Por isso, antes de se determinar como avaliar o conteúdo, a estrutura e o estilo de linguagem empregados, pelos alunos, na escrita dos poemas, considerou-se o contexto de produção no qual essas escritas ocorreram: primeiro, atentando-se à finalidade de escrever um texto para a declamação no sarau da escola e, segundo, reconhecendo a concepção de gênero construída, juntamente aos alunos, ao longo do ano letivo, pela professora, já que esta relatou desenvolver recorrentemente atividades de escrita de poemas. Ademais, considerou-se também como a SD foi construída e desenvolvida com os alunos: quais pressupostos, concepção de poema, procedimentos etc. estavam presentes na atividade de escrita desenvolvida.

Assim sendo, chegou-se a dois trabalhos importantes que nortearam a avaliação dos poemas. O primeiro foi o de Altenfelder e Armelin (2010), visto que as atividades propostas pela docente se apoiaram no material didático "Poetas da escola: caderno do professor: orientação para produção de textos", fascículo que faz parte do "Programa Escrevendo o Futuro", desenvolvido pela "Fundação Itaú Social". A escolha do tema "O lugar onde vivo", alguns poemas lidos para tratar da temática, algumas questões de interpretação sobre o tema ou mesmo questões reflexivas sobre a construção composicional do gênero foram trazidas integralmente ou adaptadas desse material.

Outro trabalho que sustentou a avaliação dos poemas escritos foi o estudo de Val e Marcuschi (2010), já que as pesquisadoras fizeram um extenso estudo avaliando 250 poemas escritos por alunos do quinto e do sexto ano do EF que participaram da "Olimpíada Brasileira de Língua Portuguesa", cujas aulas ministradas pelos docentes também adotaram a concepção de poema e atividades que compuseram a Sequência Didática trazida pelo material didático "Poetas da escola: caderno do professor: orientação para produção de textos", de Altenfelder e Armelin (2010). Assim, com o objetivo de padronizar os critérios de avaliação e de construí-la de forma mais justa possível, elaborou-se o Quadro 1, apoiado sobretudo nos trabalhos desses autores. 
Quadro 1 - Descritores observados no gênero textual Poema

\begin{tabular}{|c|c|c|c|}
\hline & NULO OU AUSENTE & PRECÁRIO OU INS UFICIENTE & ADEQUADO \\
\hline $\begin{array}{c}\text { Conteúdo Temático: } \\
\text { Autoria }\end{array}$ & $\begin{array}{l}\text { Prevalece a denotação, o } \\
\text { sujeito lírico não revela } \\
\text { suas impressões. } \\
\text { Construção da temática } \\
\text { por meio de clichês, de } \\
\text { imagens pertencentes ao } \\
\text { senso comum. }\end{array}$ & $\begin{array}{l}\text { Prevalecem os clichês e, em apenas } \\
\text { alguns versos, palavras ou } \\
\text { expressões em que o eu lírico } \\
\text { manifesta sua subjetividade, suas } \\
\text { impressões e/ou tom avaliativo. }\end{array}$ & $\begin{array}{l}\text { Tratamento crítico ou } \\
\text { humorís tico da temática e/ou } \\
\text { surpreende pela presença de } \\
\text { tom poético. }\end{array}$ \\
\hline $\begin{array}{l}\text { Estilo de Linguagem: } \\
\text { Conotação e Recursos } \\
\text { Formais Especiais }\end{array}$ & $\begin{array}{l}\text { Emprego apenas da } \\
\text { função denotativa da } \\
\text { linguagem. Ausência de } \\
\text { recursos sonoros } \\
\text { (aliteração, as sonância, } \\
\text { aliteração etc.) que } \\
\text { contribuem com a } \\
\text { significação. }\end{array}$ & \begin{tabular}{|} 
Ausência de figuras de linguagem \\
que reconstroem a realidade. \\
Ocorrem apenas metáforas \\
desgastadas ou comparações \\
desprovidas de tom poético. Não se \\
nota a ampliação da significação \\
por meio das figuras de linguagem. \\
Pouco ou nenhum recurso sonoro \\
(aliteração, assonância etc.) que \\
contribui com a significação.
\end{tabular} & $\begin{array}{l}\text { Pres ença de figuras de } \\
\text { linguagem que reconstroem o } \\
\text { real, há o inusitado: metáfora, } \\
\text { antítese, comparação, } \\
\text { personificação etc. capazes de } \\
\text { surpreender. A significação é } \\
\text { ampliada por es ses usos. } \\
\text { Pres ença de recursos sonoros } \\
\text { (aliteração, as sonância etc.) que } \\
\text { contribuem com a significação. }\end{array}$ \\
\hline $\begin{array}{c}\text { Estrutura } \\
\text { Composicional: Versos e } \\
\text { estrofes }\end{array}$ & $\begin{array}{c}\text { Quando o texto se } \\
\text { organiza em prosa } \\
\text { (organização paragrafal). }\end{array}$ & $\begin{array}{l}\text { Ainda que pareça que o texto está } \\
\text { organizado em es trofes e versos, } \\
\text { is to ocorre apenas pela falsa } \\
\text { aparência de mudança de linhas. } \\
\text { Percebe-se que há versos que não } \\
\text { possuem uma ideia coerente ou } \\
\text { completa, nota-se também palavras } \\
\text { soltas usadas como versos. }\end{array}$ & $\begin{array}{l}\text { Organização do texto em uma } \\
\text { ou mais estrofes, em que os } \\
\text { versos apres entam ideia } \\
\text { completa e contribuem com o } \\
\text { des envolvimento da temática. }\end{array}$ \\
\hline $\begin{array}{c}\text { Estrutura } \\
\text { Composicional: Rima } \\
\text { e/ou métrica }\end{array}$ & $\begin{array}{l}\text { Não se percebe } \\
\text { quais quer marcas de } \\
\text { ritmo no poema. }\end{array}$ & $\begin{array}{c}\text { Rimas e/ou métrica obtidas por meio } \\
\text { de combinações forçadas, presença } \\
\text { constante de incompatibilidade } \\
\text { vocabular ou de ideias que não } \\
\text { contribuem com o desenvolvimento } \\
\text { do tema, tudo em prol da rima ou do } \\
\text { ritmo. }\end{array}$ & $\begin{array}{c}\text { Utilização de versos mais } \\
\text { longos, mas que, metricamente, } \\
\text { garantem o ritmo do poema e/ou } \\
\text { presença de rimas ricas, aquelas } \\
\text { em que, além da regularidade } \\
\text { que garante a musicalidade, } \\
\text { contribuem com a significação. }\end{array}$ \\
\hline
\end{tabular}

Fonte: Elaborado pelos autores.

Assim sendo, os descritores expostos no Quadro 1 foram utilizados para orientar a leitura dos textos escritos pelos alunos e a descrição dos resultados, que foram 
sistematizadas no Quadro 2. Nele, os dados revelaram o percentual de alunos cujo desenvolvimento foi nulo/ausente, precário/insuficiente ou adequado dos seguintes componentes do gênero poema: Atendimento ao tema e autoria (para o Conteúdo Temático), Linguagem conotativa e recursos formais especiais (para o Estilo de Linguagem) e Versos/estrofes e rimas/métrica (para a Estrutura Composicional).

Quadro 2 - Atendimento aos componentes internos do gênero Poema escrito pelos alunos do $5^{\circ}$ ano

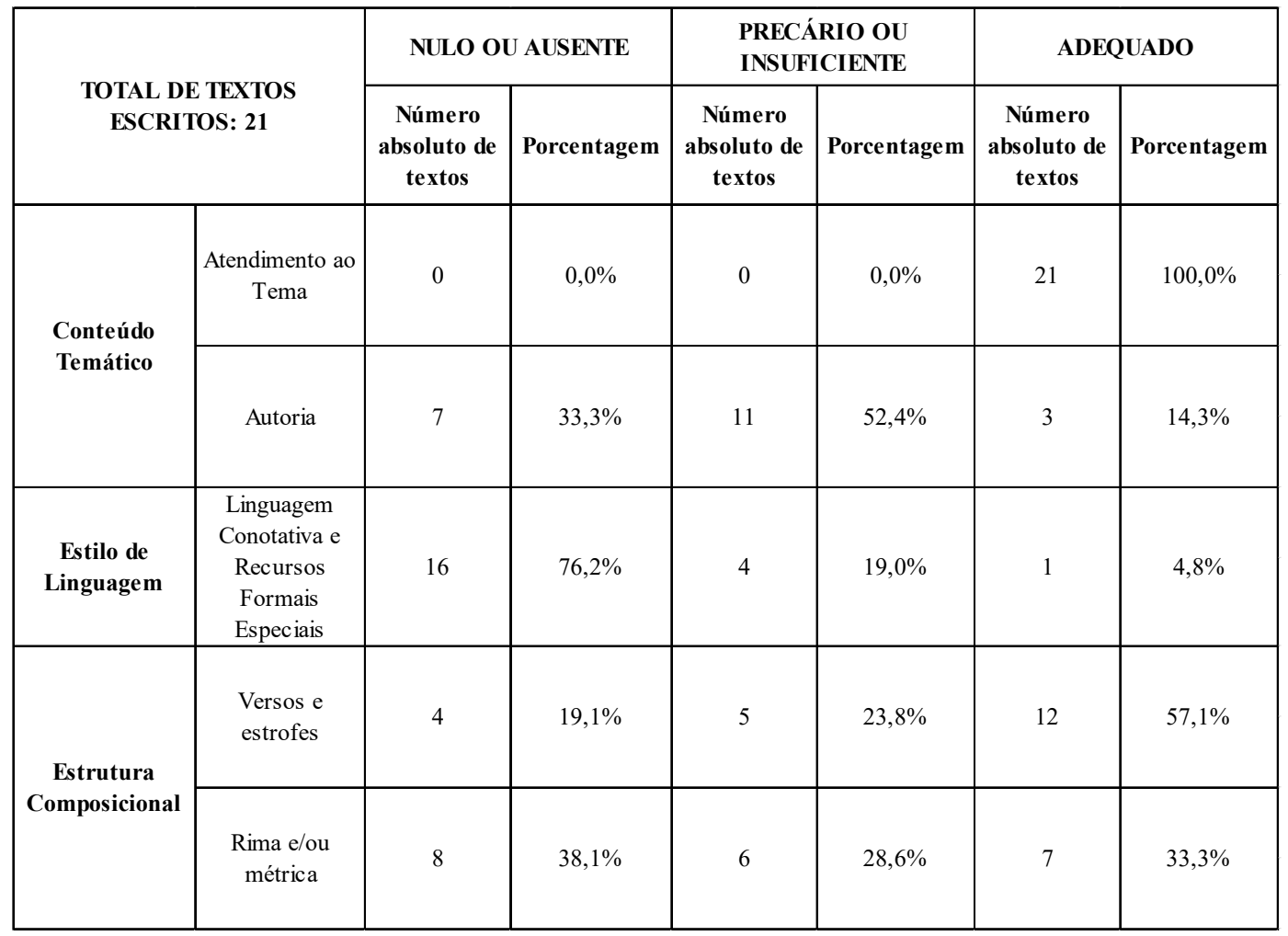

Fonte: Elaborado pelos autores.

No Quadro 2, os dados relativos ao desenvolvimento do Conteúdo Temático dos poemas revelaram, primeiramente, que todos os alunos desenvolveram o tema que foi solicitado pela docente, ou seja, todos abordaram o tema "O lugar onde vivo", não havendo fuga ao tema. Contudo, uma investigação mais profunda da temática revelou que poucos conseguiram desenvolver a autoria, apenas $14,3 \%$ de forma adequada, sendo que esse componente considerou o quanto os alunos manifestavam-se de forma crítica, humorística, irônica ou poética, o que prevaleceu, nas escritas dos 
alunos (85,7\% categorizadas como precárias ou insuficientes), foram apenas avaliações superficiais ou apreciação do espaço por meio de adjetivações, como se observa na utilização dos termos "lindo" e "bonito" no Exemplo 1, porém, sem qualquer indício de recriação da realidade, de sua apresentação de forma inusitada ou crítica.

\section{Exemplo 1 (Poema 13A)}

O lugar onde eu vivo é um lindo lugar de céu azul. Um lugar muito bonito, cheios de pessoas que eu gosto e adimiro [...]

Em outros poemas, os discentes pareciam iniciar um posicionamento mais crítico, contudo, abandonavam a ideia ou não conseguiam desenvolvê-la, o que prejudicava a construção da autoria nos textos. No Exemplo 2, o aluno revelou o amor pelo lar, contrapondo-o ao fato de morar perto de um bar, isto foi expresso pela condicional "mesmo que", porém, a ideia não foi desenvolvida completamente, o que impossibilitou depreender os motivos da crítica ao fato de se viver próximo ao bar.

\section{Exemplo 2 (Poema 9A)}

\section{[...] Amo muito meu lar}

não quero mudar

mesmo que more

perto de um bar.

Houve, no entanto, dois poemas que, respeitadas as idades das crianças, foram capazes de surpreender, de revelar impressões, sensações ou imagens inusitadas sobre o lugar onde se vive. No Exemplo 3, constatou-se a recriação do espaço por meio da analogia que o aluno fez entre o "claro" do "céu", do "sorriso das pessoas" e das "ruas". Observou-se, então, o desejo de surpreender o leitor por meio da representação do espaço de modo inusitado. 


\section{Exemplo 3 (Poema 17A)}

[...] claro e o céu

o sorriso das pessoas

as ruas também $[. .$.

O segundo componente do gênero poema analisado foi o estilo de linguagem, observando-se, sobretudo, a capacidade do aluno em desenvolver o sentido conotativo da palavra (sentido figurado), já que este aspecto é fundamental ao texto poético, uma vez que promove a ampliação da significação, sugere leituras múltiplas e a construção de imagens inusitadas da realidade. Isso também é possível quando o aluno faz uso de recursos formais sonoros (sons sugestivos), como é o caso da assonância e da aliteração, que ampliam a significação temática, ou da repetição intencional de palavras ou versos para enfatizar ou reforçar significados.

Todavia, ao contrário do que se esperava para a escrita de poemas, prevaleceu o uso denotativo da linguagem e os alunos não fizeram uso de recursos sonoros para ampliar os significados da palavra. Dos 21 textos escritos, 16 apenas descreveram o espaço e/ou o elogiaram, sem apresentar nenhum indício de linguagem figurativa e de estratégias de exploração da sonoridade com o objetivo de reforçar ou ampliar significados, o que ocorre no Exemplo 4.

\section{Exemplo 4 (Poema 19A)}

o lugar onde eu vivo

é muito bonito e lega

De se viver

E é tudo azul lá.

É uma cidade de tamanho

Porte médio, mas lá

Tem várias atrações dentro

Da cidade.

Há um lago Lá que se

Cama Lago-azul e é

Lindo de morar Lá

$\mathrm{Na}$ cidade que eu moro! 
Quanto ao uso de recursos formais, principalmente os sonoros, não se percebeu nenhum uso intencional de repetições, aliterações ou assonâncias com o objetivo de reforçar ou sugerir interpretações inusitadas. Houve apenas casos em que os alunos se valeram da repetição, sobretudo da expressão "o lugar onde eu vivo", para manter a progressão temática e não para criar um determinado efeito de sentido, como é possível notar no Exemplo 5.

\section{Exemplo 5 (Poema 15A)}

O lugar omde eu vivo

É bom e harmoniozo

Sou feliz

Por causa dele

O lugar omde eu vivo

Eu tenho amigos

Educados e parentes

Carinhosos

O lugar omde eu vivo

É saudável tem pessoas de

Todos os jeitos que possa

Imaginar

Já no Exemplo 6, classificado como insuficiente no estilo de linguagem, empregou-se a linguagem de forma mais expressiva, porém, utilizou-se uma metáfora desgastada, ou seja, um clichê para anunciar o nome da cidade da qual tratava, isto porque ele associa a cidade a uma "joia".

\section{Exemplo 6 (Poema 11A)}

\section{[...] Pensando agora}

já está na hora

de dizer o nome

de nossa joia 
Ainda que a maioria dos alunos apresentasse dificuldade no tratamento da linguagem nos poemas, visto no Exemplo 3, mostrou-se diferente, já que o aluno foi capaz de associar elementos incomuns, o que se configura, ainda que de modo simples, como um processo metafórico: "[...] claro e o céu/ o sorriso das pessoas/ as ruas também". Nesse poema, "céu", "sorriso" e "rua" ganham a mesma propriedade "claro". Essa construção revelou também o potencial criativo do aluno ao fazer um trocadilho com o nome de sua cidade, já que ele se aproveitou de parte de seu nome para criar o adjetivo "claro" que a qualifica, ou seja, fez uso de um recurso formal (o trocadilho), alcançando um estilo especial e surpreendente ao usar a linguagem, algo importante para o fazer poético.

O último componente analisado na escrita dos poemas foi a Estrutura composicional, vista sob dois aspectos: a organização do texto em estrofes e versos, cujos dados revelaram que $57,1 \%$ dos alunos conseguiram produzi-los; e obtenção de ritmo, por meio de rimas ou de métrica, o que foi alcançado adequadamente por $33,3 \%$ dos discentes. O Exemplo 7, assim como mais da metade dos outros poemas, revelou organização adequada das estrofes, já que elas serviram para dividir os versos de acordo com os diferentes espaços que eram tratados no poema; também estavam adequadas as construções dos versos, uma vez que cada verso possuía sentido completo, não havia quebras sintáticas e estabeleciam relação semântica entre si, o que contribuía com o desenvolvimento da temática.

O Exemplo 7 mostrou-se exemplar também na produção do ritmo, assim como outros 33,3\%. Nesse exemplo, é possível notar que o aluno zelou pelas rimas constantemente e elas, ainda que não contribuíssem com a reconstrução poética da realidade, não prejudicaram o desenvolvimento da temática, ou seja, não foram "forçosas". O poema também manifestou certa regularidade rítmica: muitos versos com a mesma quantidade de sílabas métricas, o que contribuiu com a melodia. Nesse sentido, esse poema mostrou-se exemplar no tratamento do eixo Estrutura Composicional. 


\section{Exemplo 7 (Poema 9A)}

Eu vivo no Brasil

minha cidade

é muito legal

O que mais gosto

É pular no quintal

Amo muito meu lar não quero mudar mesmo que more perto de um bar

Os poemas categorizados como adequados tiveram estrutura composicional semelhante ao apresentado no Exemplo 7, ainda que houvesse, por exemplo, quebra sintática em um verso ou alguma rima forçosa, que prejudicasse esporadicamente o desenvolvimento da temática, o que, no entanto, não foi o suficiente para classificá-los como precários. Contudo, 23,8\% dos poemas observados apresentaram constantes problemas como esses na constituição dos versos e foram classificados como precários na sua construção, como pode ser observado no Exemplo 8.

\section{Exemplo 8 (Poema 19A)}

O lugar onde eu vivo é muito Bonito e Legal

De se viver

e é tudo azul lá.

É uma cidade de tamanho

porte médio, mas lá

tem várias atrações dentro

Da cidade

[...]

Nota-se que, no Exemplo 8, os primeiros versos apresentaram certa organização, já que mantiveram uma relação de complementação sintática, ou seja, os 
versos possuíam uma ideia completa e coerente. Contudo, isso se perdeu ao longo do poema, sobretudo a partir da segunda estrofe, cujos versos ocorreram de modo incompleto e com sua significação fragmentada, apenas completando-se nos versos seguintes.

As quebras sintáticas foram ainda mais frequentes no Exemplo 9, parece que a única concepção do que seja verso, para esse aluno, é a ideia de que são produzidos em linhas mais curtas, deste modo, o discente, assim como outros, construiu uma espécie de parágrafo em linhas bem curtas e de tamanho semelhante para que se parecesse com versos de um poema. Ou seja, os textos apresentavam algumas palavras soltas que não produziam significados completos nos versos. Portanto, a construção de versos e de estrofes do Exemplo 9, assim como de outros três, foi considerada nula.

\section{Exemplo 9 (Poema 3A)}
A nossa
cidade é
ótima para
viver em
paz, amor
e Alegria
A nossa
praça é
especial o
nome é
sete de Setembro
[...]

Em relação à construção do ritmo, além do Exemplo 7, que tanto produziu rimas quanto estabeleceu certa regularidade métrica entre os versos, houve outros poemas que também foram classificados como adequados, uns por construir rimas ao longo de todo poema, contribuindo com a temática, mesmo sem desenvolver a métrica e outros por preservar relativamente a simetria métrica entre os versos, ainda que não construísse rimas. Contudo, $38,1 \%$ dos poemas não possuíam ritmo em nenhum excerto, a maioria desses textos foram os mesmos que também não foram capazes de construir versos com sintaxe completa, como pode ser notado 
no Exemplo 9. Ou seja, houve uma relação direta entre a dificuldade de construir versos com estrutura sintática preservada e a ausência de ritmo nos poemas.

Por fim, houve também $28,6 \%$ dos poemas em que o ritmo foi categorizado como precário. Boa parte desse resultado se deve ao fato de os poemas, em algum momento, produzirem rimas simples, mas, ao longo da produção, abandonarem esse recurso. Também foi recorrente a produção de rimas forçosas, o que significa que a busca pelas rimas se sobrepôs ao desenvolvimento produtivo e criativo da temática, como pode ser visto no Exemplo 10, no qual o discente não foi capaz de trazer à tona o lugar onde vive, entretanto, conseguiu, por meio das rimas e do recurso da repetição, conferir ritmo ao poema.

\section{Exemplo 10 (Poema 6A)}

Na minha cidade

tem ação

Ela também tem

um céu azulão

Todo dia

tem ação

E todo dia tem

Emocao no coração

Todo dia a

ação é plena

Aprendendo um tema

Em síntese, os resultados expressos revelaram tanto aspectos positivos quanto negativos na escrita dos poemas. De positivo, avalia-se a capacidade de desenvolvimento do tema, que foi $100 \%$ atendida pelos alunos, já que nenhum mostrou-se incapaz de produzi-los. Também se mostrou positiva a elaboração de versos e de estrofes (do componente Estrutura Composicional), pois, ainda que muitos alunos os produzissem de modo precário, a maioria $(80,9 \%)$ conseguiu, em certa medida, construi-los. No entanto, no componente Estrutura Composicional, os resultados apresentaram-se de modo mais negativo quanto à produção de rimas e/ou métrica. 
Os dados mais preocupantes foram os relacionados ao desenvolvimento da autoria (do eixo Conteúdo Temático) e ao Estilo de Linguagem empregados nos poemas. Isso porque, além de apresentarem, como expresso no Quadro 2, baixo índice de produções adequadas, também revelaram a ausência desses componentes em uma quantidade significativa de poemas, sobretudo no que se refere ao uso da linguagem conotativa e de outros recursos formais da linguagem poética, já que $76,2 \%$ dos alunos não tiveram aproveitamento algum na avaliação do Estilo de Linguagem poético.

\section{Considerações finais}

Diante dos resultados das escritas dos poemas por alunos do $5^{\circ}$ ano do Ensino Fundamental, algumas discussões em torno das características dessas escritas e da forma como a professora organizou e aplicou a atividade são necessárias para que se conclua até que ponto a organização didática, as atividades e as intervenções propostas influenciaram na escrita dos textos. $O$ primeiro aspecto a ser ressaltado é o de que os alunos foram capazes de produzir gêneros textuais e que os poemas (uns mais, outros menos) são capazes de funcionar socialmente, em especial pela sua adequação ao tema, alcançado por todos os textos, e pela construção composicional em versos e estrofes que, em maior ou menor escala, foi obtida pela maioria dos alunos. Entretanto, os resultados também revelaram alguns componentes mais frágeis na escrita dos poemas, dentre eles estão o desenvolvimento da linguagem conotativa e de outros recursos formais para alcançar a plasticidade da linguagem poética e o desenvolvimento da autoria.

Esta pesquisa estabelece uma relação direta entre tais resultados e as práticas desenvolvidas durante as Sequências Didáticas pela docente e a principal relação refere-se à leitura e ao estudo de outros poemas que subsidiaram as escritas. Os resultados obtidos no desenvolvimento do componente conteúdo temático evidenciaram a importância da leitura e do estudo do gênero antes do processo de escrita: ao ler, com os alunos, diversos poemas e ao discutir constantemente o tema "O lugar onde vivo", a professora fez com que $100 \%$ dos alunos se adequassem ao tema requerido. Contudo, a professora não trabalhou a necessidade de os alunos escreverem textos autorais, expressando-se criticamente, com ironia, com humor etc., e os resultados, por sua vez, revelaram que apenas 14,3\% dos alunos expressaram algum grau de autoria em seus poemas. 
O trabalho com a leitura também se mostrou valioso para o desenvolvimento da construção composicional dos poemas em versos e em estrofes. A realização das leituras de poemas, as discussões em torno de sua organização em versos, em estrofes e com presença de rimas, além de exercícios escritos para revisão da estrutura dos poemas fizeram com que $57,1 \%$ dos alunos fizessem uso adequado dessa estrutura e outros $23,8 \%$ obtivessem êxito parcialmente. Ou seja, o trabalho de ler, de reconhecer as estrofes e versos, de contá-los, de estudá-los e de conceituá-los resultou na estrutura composicional desejada para os poemas.

Porém, o componente estilo de linguagem conotativo e outros recursos estilísticos capazes de ampliar a significação e trazer múltiplos significados ao poema não foram estudados, o que resultou em apenas um texto conseguindo alcançar tal estilo. Atribui-se, portanto, esse resultado negativo à ausência de atividades de estudo da linguagem poética e de outras intervenções que propusessem a revisão da linguagem adotada. As intervenções de linguagem feitas pela professora ocorreram apenas no sentido de editar os textos escritos, corrigindo somente os erros de ortografia e de concordância verbal e nominal, o que, ainda assim, não foi capaz de solucionar todos os desvios de uso da linguagem padrão.

Assim sendo, este estudo admite que as atividades de leitura do gênero poema para o estudo de suas características promoveram bons resultados na escrita do gênero, contrariamente, quando isso não foi feito, alguns componentes foram insuficientemente desenvolvidos ou mesmo não aconteceram. A observação da SD comparada aos resultados obtidos nos textos dos alunos revelaram que as características do gênero que foram estudadas por eles a partir de leituras, de análises, de questionamentos ou de discussões foram mais recorrentes em suas escritas. Já as características não trabalhadas foram justamente aquelas que os discentes mais tiveram dificuldade ou não conseguiram desenvolver em seus textos.

Dessa forma, esta pesquisa constata o impacto que a SD tem sobre a escrita de um gênero textual, em especial o quanto as intervenções feitas pelo docente antes e após a escrita da primeira versão do texto podem provocar resultados significativos na construção do gênero textual. Essa relação direta das atividades contempladas pela SD com os bons resultados das escritas dos alunos e, contrariamente, a ausência de alguns estudos que resultaram em pontos mais frágeis nessas escritas dialoga com os estudos de Souza (2015), os quais constataram avanços no desenvolvimento da linguagem de cartas pessoais, sobretudo soluções gramaticais, após a aplicação de módulos de intervenção que visavam sanar tais dificuldades, além de avanços no desenvolvimento da temática. 
Isso permite que esta pesquisa defenda que as atividades de intervenção poderiam auxiliar os alunos a eliminar ou a minimizar as defasagens no tratamento da linguagem escrita dos poemas. Nesse sentido, atividades de leitura e de interpretação, por exemplo, poderiam intervir solucionando as dificuldades com o uso conotativo das palavras, obtendo significados inesperados, combinações surpreendentes entre as palavras, fazendo com que um número maior de alunos conseguisse usar adequadamente a linguagem poética.

Portanto, os resultados das escritas dos alunos relacionados às atividades desenvolvidas pela docente permitem que este estudo conclua primeiramente que a presença da SD é necessária para o sucesso da escrita do gênero. Porém, a SD pode contribuir muito ou pouco para essas escritas: colaborará mais quando os docentes elaborarem as intervenções de acordo com as dificuldades apresentadas pelos alunos na escrita do gênero textual e menos quando apenas propor atividades de correção sem se atentar às reais necessidades/dificuldades de escrita do grupo. Assim sendo, conclui-se que as intervenções pontuais realizadas no Ensino Fundamental I, como fez a professora ao trabalhar a construção dos versos e das rimas e o tema dos poemas, foram capazes de fazer com que os alunos desenvolvessem o que foi estudado no gênero. Ao contrário, as correções "tradicionais", que apenas apontaram os erros, produziram pouca ou nenhuma melhoria nas escritas.

Em síntese, os resultados aqui expostos e as discussões realizadas não servem para apontar os responsáveis pelos problemas encontrados na escrita dos poemas, mas são importantes para se reconhecer que o sucesso da escrita depende muito da elaboração das SD, o qual ocorre apenas quando há a aproximação do aluno (autor) com o texto (objeto a ser conhecido) e com o professor-mediador (aquele que apresenta o que ainda não se sabe). A Sequência Didática é, então, o elo que aproxima os três e promove, assim como defendido por Schneuwly e Dolz (2004), o aprendizado do gênero textual por meio de sua apresentação (com leituras, estudos, discussão e observação do que os alunos já sabem), da escrita da primeira versão do texto (e identificação do que ainda é necessário aprender), dos módulos de intervenção (atividades orais, em dupla, em grupos, coletivas, exercícios de reflexão, reescritas, roteiros de correção, autocorreção, troca de textos entre os pares, revisão orientada, leituras de textos do mesmo gênero e de outros gêneros etc.) e da produção final (a fim de avaliar o que foi aprendido). 


\section{Nota}

1 Todos os exemplos citados pertencem ao corpus utilizado neste estudo e são transcrições das versões finais escritas pelos alunos, cujo conteúdo, linguagem e estrutura empregados nos poemas foram integralmente preservados, mantendo inclusive possíveis desvios da norma culta da Língua Portuguesa e outros problemas encontrados.

\section{Referências}

ALTENFELDER, A.H.; ARMELIN, M.A. Poetas da escola: caderno do professor: orientação para produção de textos. São Paulo: Cenpec, 2010. [Coleção da Olimpíada]. Disponível em: http://dediadema.edunet.sp.gov.br/Downloads/OLP 2014/Caderno de Poemas.pdf. Acesso em: 10 out. 2017.

BAKHTIN, M. Os gêneros do discurso. In: BAKHTIN, M. Estética da criação verbal. 6. ed. São Paulo: Martins Fontes, 2003.

BRASIL. Secretaria de Educação Fundamental. Parâmetros curriculares nacionais: língua portuguesa. Brasília, 1997. 144 p. Disponível em: http://portal.mec.gov.br/seb/arquivos/pdf/livro02. pdf. Acesso em: 27 jan. 2015.

BRASIL. Pró-letramento: programa de formação continuada de professores dos anos / séries iniciais do ensino fundamental: alfabetização e linguagem. Brasília: Ministério da Educação: Secretaria de Educação Básica, 2012.

GALVÃO, M.N.O.M. A leitura e a produção textual no Ensino Fundamental I: uma proposta de como trabalhar com os gêneros textuais. 2015. 343 f. Dissertação (Mestrado) - Curso de Mestrado Profissional em Letras - PROFLETRAS, Centro de Ensino Superior do Seridó - Ceres, Universidade Federal do Rio Grande do Norte - UFRN, Currais Novos, 2015. Disponível em: http:// bdtd.ibict.br/vufind/Record/UFRN_591f6318c546ffac11fc43564c5872b5. Acesso em: 02 jul. 2017.

MARCUSCHI, L.A. Gêneros textuais: definição e funcionalidade. In: DIONISIO, A.P.; MACHADO, A.R.; BEZERRA, M.A. (org.). Gêneros textuais e ensino. Rio de Janeiro: Lucerna, 2002.

Cap. 1. p. 19-36.

MORTATTI, M.R.L. História dos métodos de alfabetização no Brasil. 2006. Conferência proferida durante o Seminário "Alfabetização e letramento em debate", promovido pelo Departamento de Políticas de Educação Infantil e Ensino Fundamental da Secretaria de Educação Básica do Ministério da Educação. Disponível em: http://portal.mec.gov.br/seb/arquivos/pdf/Ensfund/ alf_mortattihisttextalfbbr.pdf. Acesso em: 25 jul. 2016.

SANTOS, C.F.; MENDONÇA, M.; CAVALCANTE, M.C.B. Trabalhar com texto é trabalhar com gênero? In: SANTOS, C.F.; MENDONÇA, M.; CAVALCANTE, M.C.B. (org.). Diversidade textual: os gêneros na sala de aula. Belo Horizonte: Autêntica, 2007. Cap. 2. p. 27-42. Disponível em: http://www.nigufpe.com.br/wp-content/uploads/2012/09/Diversidade_Livro.pdf. Acesso em: 03 jan. 2017.

SCHNEUWLY, B.; DOLZ, J. Gêneros orais e escritos na escola. Campinas: Mercado de Letras, 2004. 
SOARES, M. Letramento: um tema em três gêneros. 2. ed. Belo Horizonte: Autêntica, 2006.

SOUZA, A.M.L. Produção de texto: a revitalização de um gênero em extinção. 2015. 145 f. Dissertação (Mestrado) - Curso de Pós-graduação - Mestrado Profissional em Letras (PROFLETRAS), Universidade do Mato Grosso do Sul, Três Lagoas, 2015. Disponível em: http://bdtd. ibict.br/vufind/Record/UFMS_1a1195158c43f5638e4c462d8ee3ca9c. Acesso em: 02 jul. 2017.

TFOUNI, L.V. Escrita, alfabetização e letramento. In: . Letramento e alfabetização. 7. ed. São Paulo: Cortez, 2005. Coleção Questões da Nossa Época; v. 47. Cap. 1. p. 9-28.

VAL, M.G.C. Produção escrita: trabalhando com gêneros textuais. Belo Horizonte: Ceale/FaE/ UFMG, 2007. 68 p. (Coleção Alfabetização e Letramento). Disponível em: http://www.ceale.fae. ufmg.br/pages/view/10-producao-escrita-trabalhando-com-generos-textuais.html. Acesso em: 01 jun. 2016.

VAL, M.G.C.; MARCUSCHI, B. Poemas na escola: análise de textos de aluno. Educação em Revista, [s.l.], v. 26, n. 2, p. 65-88, ago. 2010. FapUnifesp (SCIELO). Disponível em: http://www. scielo.br/pdf/edur/v26n2/a04v26n2.pdf. Acesso em: 06 jun. 2017. 